\title{
Malaria relevance and diagnosis in febrile Burkina Faso travellers: a prospective study
}

\author{
Stéphanie Schrot-Sanyan ${ }^{1 *}$, Sylvie Gaidot-Pagnier ${ }^{1}$, Ahmed Abou-Bacar ${ }^{1}$, Sodiomon Bienvenu Sirima² \\ and Ermanno Candolfi ${ }^{*}$
}

\begin{abstract}
Background: There is a lack of information regarding the epidemiology of malaria among travellers from nonmalaria endemic countries to Sahelian areas. The literature provides general statistics about imported malaria in industrialized countries or extensive recommendations about fever management, but none of these recommendations are applicable to developing countries.

Methods: The aim of the study was to evaluate the aetiologies of fever, malaria prevalence, and best diagnostic methods in a population of 306 non-malaria endemic travellers who, over a one-year period, consulted the French embassy's Centre Médico-Social in Ouagadougou (Burkina Faso) for fever. All patients underwent a clinical examination, a questionnaire, and three different malaria tests: thick blood film, QBC-test and HRP-2-based rapid diagnostic test.

Results: Fever was caused by malaria in 69 cases (23\%), while 37 (12\%) were due to Pneumonia and 35 cases (8\%) to ENT infections. Fever remained unexplained in 87 patients (51.3\%). Malaria prevalence varied throughout the year: about $90 \%$ of malaria cases were diagnosed during and after the rainy season, between July and December, with up to $50 \%$ malaria prevalence for fever cases in October. Malaria diagnosis based solely on clinical signs, combined or not, leads to about $80 \%$ of unnecessary treatments.Although anti-malarial chemoprophylaxis was used in only $69 \%$ of shortstay patients (who travelled for less than three months), this was effective. Under local conditions, and using blood film examination as the reference method, the QBC test appeared to be more reliable than the HRP-2-based rapid diagnostic test, with respective sensitivities of $98.6 \%$ versus $84.1 \%$, and specificities of $99.6 \%$ versus $98.3 \%$.

Conclusions: Reliable biological diagnosis of malaria among travellers from non-malaria endemic countries in Sahelian areas is necessary because of low malaria prevalence and the poor performance of clinical diagnosis. A fever during the first half of the year requires investigating another aetiology, particularly a respiratory one. Malaria chemoprophylaxis is efficient and must not be overlooked. The QBC test appears to be the most reliable diagnostic test in this context.
\end{abstract}

Keywords: Malaria, QBC, HRP2, Fever, Burkina Faso

\section{Background}

In Burkina Faso, a Sahelian country in West Africa, malaria transmission is holoendemic, with a very low permanent transmission and a very strong seasonal component [1-4]. Each year, there are approximately 1,5 million malaria cases and 40,000 victims; $90 \%$ of them are children under 15 years of age [5-7]. Approximately 20,000 French people travel to Burkina Faso each year, and 3,200 settle there permanently [8].

\footnotetext{
*Correspondence: stephschrot@gmail.com; candolfi@unistra.fr

'Institut de Parasitologie et de Pathologie Tropicale, EA 4438, Université de Strasbourg, Strasbourg, France

${ }^{2}$ Centre National de Recherche et de Formation sur le Paludisme, Ministère de la Santé, Ouagadougou, Burkina Faso
}

There are some general statistics regarding malaria importation in industrialized countries. With a general prevalence for malaria in sub-Saharan Africa travellers of one to four per $1,000[9,10]$, the prevalence of fever due to malaria after travelling to a tropical country is quite variable, ranging from $27 \%$ to $52 \%$ [11-15], and malaria among patients consulting in Europe after a travel in sub-Saharan Africa is $20 \%$ in 2009 [16]. However, this data was collected in hospitals or specialist settings, or from a specific population. The different "tropical" destinations, though varied, were not specifically identified in these studies. Burkina Faso often appeared in the "subSaharan Africa" category, which brought together sanitary

\section{Biomed Central}


situations as varied as those in Sahelian and equatorial areas. The literature provides different recommendations about fever management and malaria suspicion after travelling to a tropical country [17-20]. These recommendations are very extensive, but are not applicable to a developing country, where physicians are rare and tests not always available or reliable: if malaria diagnosis is unproblematic in Europe, where laboratories are required to provide a diagnosis within 2 hours, the same cannot be said for malaria diagnosis in endemic countries [21-31]. Then, the only safe solution for patients is to use an "Emergency Standby Treatment for Malaria" [32].

But a medical structure must be able to establish a reliable diagnosis and trust its own assays.

The aim of this study was to determine malaria prevalence and other main aetiologies of fever among febrile patients from non-malaria endemic countries, according to the length of their stay in Burkina Faso. Microscopic quantitative buffy coat test $(\mathrm{QBC})$, which was used during consultations, was compared to the non-microscopic rapid diagnostic test (RDT), which targets the histidinerich protein-2 (HRP2) of Plasmodium falciparum.

\section{Methods}

\section{Inclusion criteria}

This study was conducted at the French embassy's Centre Médico-Social (CMS) in Ouagadougou (Burkina Faso). This is a small primary health centre that treats predominately French embassy staff and travellers living in or passing through Burkina Faso and coming from non-malaria endemic countries. From this population, patients over 15 years of age who had spent the first five years of their life outside of a malaria-endemic area and had "suspicion of malaria" between July 2006 and July 2007 were recruited. "Suspicion of malaria" was defined as "febrile syndrome" in the last 48 hours, for fever remained the most sensible clinical sign of malaria [33,34]. "Febrile syndrome" was defined as an uncorrected axillary temperature over $37.5^{\circ} \mathrm{C}$, as measured at the air-conditioned CMS, at home, or by acute febrile signs including shivers, hot flashes, and sweating.

\section{Data collection}

During the consultation, an oral consent was informed for each patient. A questionnaire was completed with the patient with the following information:

- Malaria chemoprophylaxis;

- Anti-malarial and antipyretic treatment taken over the last few days;

- Travels outside Burkina Faso over the last few weeks.

All patients underwent an examination. Uncorrected axillary temperature of each patient prior to the clinical examination was measured. Patients with temperature above $38.0^{\circ} \mathrm{C}$ were considered as "febrile on examination".

Using a sterile lancet, blood samples were collected via finger prick for three malaria tests:

- QBC-test: 50-65 $\mu \mathrm{l}$ of blood was drawn into an acridine orange-coated heparinized capillary tube, handled according to the manufacturers' recommendations [35], and read on site,

- HRP2-based RDT (Palutop ${ }^{\circ}$ from the Alldiag, Strasbourg, France): one drop of blood with solvent was read on site under oil immersion after 15 minutes according to the manufacturers' recommendations [36],

- Thick and thin blood films were used to establish a reference diagnosis: one slide with four blood drops [three for the Giemsa-stained thick film (GTF) and one for the thin blood film]. These slides were coloured once a week with Giemsa at the Centre National de Recherche et de Formation sur le Paludisme in Ouagadougou, a public health research centre in Ouagadougou. The slides were read at the end of the study following the Centre's protocol: the slides were examined by two experienced researchers (and possibly by a third expert in case of disagreement between the two. Parasitaemia was calculated on the thick film by the number of trophozoites for 10 leucocytes, and the species was determined on the thin film when the thick film was positive. About $10 \%$ of these slides (taken at random) and all of the conflict cases (in which one of the three tests showed a different result from the other two) were re-read (complete reading of the thick and thin films) at the Institut de Parasitologie et de Pathologie Tropicale de Strasbourg in order to establish a final reference diagnosis.

\section{Diagnosis and patient management}

This study was non interventional. Since the final reference diagnosis was not known at the time of consultation, the QBC-test result was taken into account so as to determine whether to treat the patients for malaria, as the physicians of the CMS usually did. When the QBC-test was positive, patients were treated according to national guidelines:

- Non-complicated malaria: association of lumefantrine $(120 \mathrm{mg})$ and artemether $(20 \mathrm{mg})$, 6 times four tablets every 12 hours;

- Complicated malaria [37]: $8 \mathrm{mg} / \mathrm{kg}$ of intravenous quinine every 8 hours, with an initial bolus of 16 $\mathrm{mg} / \mathrm{kg}$ and relay with oral quinine 48 hours after the last febrile seizure for 10 days of treatment, at the same dosage. 
When the QBC-test was negative, further investigations were eventually carried out by the physicians of the CMS, according to the clinical status, to determine the aetiology of the observed febrile syndrome, such as urinary cultures for pyelonephritis and chest x-rays for pneumonia. No anti-malarial treatment was initiated without a positive $\mathrm{QBC}$ test.

\section{Data analysis}

For statistical analysis, Chi-squares $\left(\mathrm{x}^{2}\right)$ or Student-t-tests (t-test) were used, as appropriate. Bilateral analysis was computed, and the significance level was set at 0.05 .

\section{Results}

Over a one-year period, informed consent was obtained from 306 patients consulting for febrile syndrome: 149 males and 157 females. Patients were separated into two groups according to the amount of time spent in Burkina Faso: patients that stayed longer than three months were labelled "resident" (202) and those that stayed less than three months were labelled "traveller" (104).

The distribution varied throughout the year. "Travellers" were most often present (and, therefore, attended medical consultation) during summer and Christmas vacations or during the international film festival in February (FESPACO), while "residents" were present year-round. Two peaks of consultation for febrile syndrome were noted in the "resident" population: the first in October, just after the rainy season, and the second one in February, before the start of the hot season.

\section{Fever on examination}

We first evaluated antipyretics as potentially confounding factor, following the Mantel-Haenszel method. The stratificated ORs of patients with and without antipyretics were compared to determine if an effect modification or interaction was indeed taking place between those two variables. There was no statistical interaction neither with patients considered "febrile on examination" (OR O,91, $[0,47-1,74])$ nor with malaria (OR 0,76 [0,36-1,62]).

Of the 57 patients who were "febrile on examination" (patients with an uncorrected axillary temperature over $38.0^{\circ} \mathrm{C}$ ), only 22 had malaria $(38.6 \%)$, which is a significantly higher percentage than that of the 47 malaria cases (18.9\%) among the 249 "non-febrile patients on examination" $\left(\chi^{2}, p<0.001\right)$.

Malaria and other aetiologies of fever throughout the year Aetiologies of fever are reported in Table 1. Of the 306 patients, 69 were diagnosed with malaria (22.6\%): 67 P. falciparum (97.1\%) including two mixed infections with Plasmodium malariae, and one with $P$. malariae only. In the last case, no species could be determined, due to an extremely low parasitaemia (post-treatment
Table 1 Fever aetiologies in $\mathbf{3 0 6}$ adults from non-malaria endemic countries living or travelling in Burkina Faso

\begin{tabular}{ll}
\hline Undefined fever & \\
$\quad$ With acute digestive symptomatology & $87(28.4 \%)$ \\
$\quad$ Without acute digestive symptomatology & $70(22.9 \%)$ \\
Malaria & $69(22.6 \%)$ \\
Pneumonia & $37(12.1 \%)$ \\
ENT infections & $35(7.8 \%)$ \\
Pyelonephritis & $4(1.3 \%)$ \\
Erysipelas & $4(1.3 \%)$ \\
\hline Total & $306(100 \%)$ \\
\hline
\end{tabular}

diagnosis, with very low positive GTF and negative thin blood film).

Most malaria cases (88.4\% of diagnoses [Figure 1]) were concentrated between July and December, with a peak in October-November, approximately one month after the precipitous peak of the rainy season. The maximal malaria prevalence (nearly 50\%) was in October-November among both "travellers" and "residents" (Figure 2).

In January, three patients diagnosed with malaria reported having travelled outside Burkina Faso in the previous month (two to Ghana and one to Mali near the river Niger), as well as one in February (Mali).

\section{Malaria and chemoprophylaxis}

Following the national and international recommendations, a long-term prophylaxis was not recommended to the residents, but only $69 \%$ of the travellers correctly took one. Only one of them (a "traveller") who took chemoprophylaxis correctly suffered from malaria (Table 2). This young, 20-year-old patient took a prophylaxis based on a chloroquine and proguanil association in accordance with current recommendations [38] (level 2 in 2006) of the Institut de Veille Sanitaire, the French

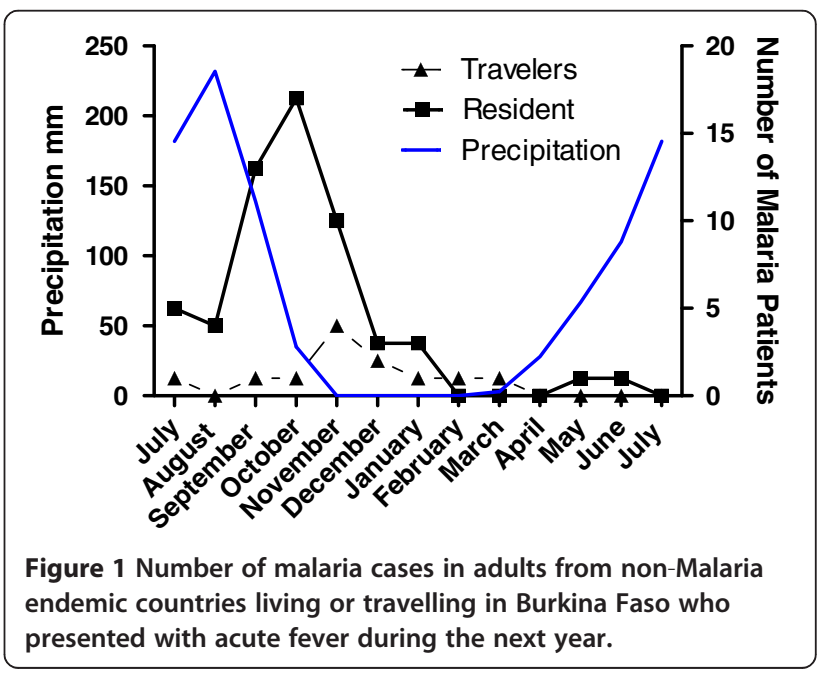




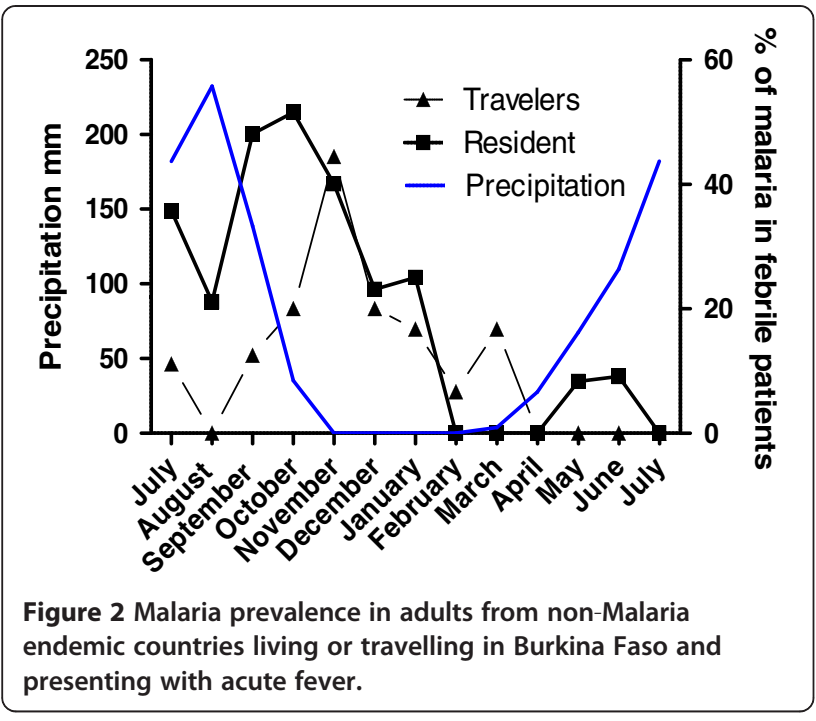

institute of public health. She was travelling in the southern part of Burkina Faso that borders the Ivory Coast. A higher anti-malarial drug resistance was recorded in Ivory Coast and a different prophylaxis is recommended (level 3 , mefloquine or a proguanil and atovaquone association).

\section{Clinical signs and their association with malaria}

Five categories for patient symptoms were determinate: digestive (vomiting, abdominal pain, diarrhoea, etc.), earnose-throat (ENT) (rhinitis, pharyngitis, odynophagia...), respiratory, urinary, and cutaneous. Those that did not correspond with any of these categories were considered "isolated fevers". Table 3 shows the signs' prevalence by malaria cases and non-malaria cases.

The performance of the best symptom or association of symptoms for malaria diagnosis in this study is displayed on Table 4. Isolated fever was the most frequent

Table 2 Malaria prevalence according to the length of stay and malaria chemoprophylaxis in $\mathbf{3 0 6}$ febrile adults from non-Malaria endemic countries living or travelling in Burkina Faso

\begin{tabular}{|c|c|c|c|}
\hline & & Non malaria & Malaria \\
\hline \multirow[t]{4}{*}{$\begin{array}{l}\text { Journeys under } \\
3 \text { months }\end{array}$} & $\begin{array}{l}\text { With adapted and well-taken } \\
\text { chemoprophylaxis }\end{array}$ & 71 & 1 \\
\hline & Malaria prevalence & & $1.4 \%$ \\
\hline & $\begin{array}{l}\text { Without appropriate } \\
\text { chemoprophylaxis }\end{array}$ & 21 & 11 \\
\hline & Malaria prevalence & & $34.4 \%$ \\
\hline \multirow[t]{4}{*}{$\begin{array}{l}\text { Journeys over } \\
3 \text { months }\end{array}$} & $\begin{array}{c}\text { With adapted and well-taken } \\
\text { chemoprophylaxis }\end{array}$ & 27 & 0 \\
\hline & Malaria prevalence & & $0 \%$ \\
\hline & $\begin{array}{l}\text { Without appropriate } \\
\text { chemoprophylaxis }\end{array}$ & 118 & 57 \\
\hline & Malaria prevalence & & $32.6 \%$ \\
\hline
\end{tabular}

clinical sign for malaria (78.3\%), but more than half of these isolated fevers were related to another origin. There were significantly more fevers on clinical examination in the malaria group.

\section{Malaria diagnosis}

To predict the performance of on-the-spot, available tests, namely the HRP2- based RDT and QBC-tests, these tests were performed in addition to thick and thin blood film examinations for each patient. The results of these three tests were coincident in $94 \%$ of the patients (289/306). The results of the tests' diagnosis performance are summarized in Table 4.

\section{Discussion}

\section{Malaria diagnosis}

The QBC-test is quick and easy to use: every physician was trained for approximately one hour, and the test's complete implementation took less than 10 minutes. The main inconvenience was the material: the initial investment is important (centrifuge, microscope with oil immersion). In a clinical laboratory in Ouagadougou in 2013, the cost of a QBC-test for the patient is between 1,500 and 2,000 XOF $(2-3 €)$; this not much more expensive than for a GTF who will cost 1,000 to 1,500 XOF (1,5 to $2 €$ ) [39]. The logistics (management of colouring agents and colourings) are less binding comparing to a GTF, because every test can be analysed individually. The Becton-Dickinson company, which developed this technique, stopped marketing the test's in 2006 [40], but the assay commercialization was taken over by QBCDiagnostics, which continues to develop new and less

Table 3 Symptoms associated with fevers in $\mathbf{3 0 6}$ adults travelling in Burkina Faso, regardless of the link to malaria

\begin{tabular}{cccc}
\hline Symptom & $\begin{array}{c}\text { Non-malaria } \\
\text { patients } \\
\mathbf{2 3 7}\end{array}$ & $\begin{array}{c}\text { Malaria } \\
\text { patients }\end{array}$ & Total \\
\hline ssolated fever & 68 & $\mathbf{6 9}$ & $\mathbf{3 0 6}$ \\
Prevalence & $28.7 \%$ & $78.3 \%$ & 122 \\
Digestive symptoms & 88 & 9 & $39.9 \%$ \\
Prevalence & $37.1 \%$ & $13.0 \%$ & $37.7 \%$ \\
ENT symptoms & 37 & 5 & 42 \\
Prevalence & $15.2 \%$ & $7.3 \%$ & $13.7 \%$ \\
Respiratory symptoms & 36 & 1 & 37 \\
Prevalence & $15.2 \%$ & $1.5 \%$ & $12.1 \%$ \\
Urinary symptoms & 4 & 0 & 4 \\
Prevalence & $1.7 \%$ & & $1.3 \%$ \\
Cutaneous symptoms & 4 & 0 & 4 \\
Prevalence & $1.7 \%$ & & $1.3 \%$ \\
\hline
\end{tabular}


Table 4 Statistical value of clinical signs, association of clinical signs and malaria tests (QBC and HRP2-based RDT) for the diagnosis of malaria, according to the results of the thick and thin Giemsa-stained blood films, considered to be the gold standard method (with $\mathbf{9 5 \%}$ confidence intervals for sensibility and specificity)

\begin{tabular}{|c|c|c|c|c|}
\hline & Sensibility & Specificity & $\begin{array}{c}\text { Positive predictive } \\
\text { value }\end{array}$ & $\begin{array}{c}\text { Negative predictive } \\
\text { value }\end{array}$ \\
\hline \multirow{2}{*}{ Isolated fever } & $78.3 \%$ & $71.3 \%$ & \multirow{2}{*}{$44.3 \%$} & \multirow{2}{*}{$91.9 \%$} \\
\hline & {$[68.5-88.0]$} & {$[65.6-77.1]$} & & \\
\hline \multirow[t]{2}{*}{ Fever present on examination } & $31.9 \%$ & $85.2 \%$ & \multirow{2}{*}{$38.6 \%$} & \multirow{2}{*}{$81.1 \%$} \\
\hline & {$[20.9-42.9]$} & {$[80.7-89.8]$} & & \\
\hline \multirow[t]{2}{*}{ Isolated fever present on examination } & $26.1 \%$ & $96.2 \%$ & \multirow{2}{*}{$66.7 \%$} & \multirow{2}{*}{$81.7 \%$} \\
\hline & {$[15.7-36.5]$} & {$[93.8-98.6]$} & & \\
\hline \multirow[t]{2}{*}{ Digestive symptoms } & $13.0 \%$ & $62.9 \%$ & \multirow{2}{*}{$9.3 \%$} & \multirow{2}{*}{$71.3 \%$} \\
\hline & {$[5.1-21.0]$} & {$[57.2-69.4]$} & & \\
\hline \multirow[t]{2}{*}{ QBC } & $98.6 \%$ & $99.6 \%$ & \multirow{2}{*}{$98.6 \%$} & \multirow{2}{*}{$99.6 \%$} \\
\hline & {$[9.7-100]$} & {$[98.8-100]$} & & \\
\hline HRP2 & $84.0 \%$ & $98.0 \%$ & \multirow{2}{*}{$92.0 \%$} & \multirow{2}{*}{$95.0 \%$} \\
\hline (for P. falciparum) & {$[75.4-92.7]$} & {$[96.7-99.9]$} & & \\
\hline
\end{tabular}

cumbersome devices [41]. The capillary tube enables a blood cell count obtained in a few minutes, which may be especially helpful when the fevers are unrelated to malaria, as observed in approximately $80 \%$ of cases.

The QBC-test offers more than a reliable performance: sensitivity and positive predictive value over $98 \%$, and specificity and negative positive value over $99 \%$. These figures are much superior to those found in the local GTF-using laboratories [27-29]: there was only one false-positive and one false-negative, both observed during post-treatment. However, the test did not allow identifying the species in the only case of $P$. malariae infection. This likely caused overtreatment via artemisinin-derivatives when chloroquine treatment would have been sufficient. Nonetheless, the benefit/risk balance remains much more favourable for the QBC-test, when more than $97 \%$ of the malaria cases were due to P. falciparum.

RDT was significantly overall less sensitive than the QBC, as confirmed by several studies [42,43]: the number of false-negatives by antigen HRP2 detection is high (15.9\%). RDT remains useful only under conditions in which it is the only test available, and the results must be interpreted carefully: a negative test must be repeated in the absence of clinical improvement. A RDT costs between 4,000 to 10,000 XOF (6 to $15 €$ ) in Ouagadougou in 2013.

The RDT remains an asset in retrospective diagnosis, when PCR is not available: $10 \%$ of our patients, prior to fever consultation, had already undergone malaria treatment. In one of these cases, QBC did not diagnose malaria, whereas the RDT would have been able to make the diagnosis. Four other patients, who had also already undergone treatment, exhibited negative direct microscopic test (QBC and GTF), along with a positive RDT; we wonder whether these were authentic malaria cases, though masked by treatment. This would have changed patient management: in the case of proven malaria, post-treatment observation would be increased, and in the case of a negative test, we would direct our search towards another aetiology.

\section{Malaria prevalence and other aetiologies of fever}

Malaria was the second highest fever diagnosis behind unexplained fevers, with a prevalence from $22.6 \%$. The rate among African residents in Ouagadougou was not different, and was between $17 \%$ and $20 \%$ [44]. The malaria prevalence among "residents" with febrile syndrome was $28.2 \%$ on average, which was significantly higher than that among "travellers" $\left(11.5 \%, \chi^{2}, p<0.001\right)$. With respect to the malaria cases, $82.6 \%$ were diagnosed among "residents", even though they represented only $66 \%$ of total patients.

Pneumonias were the third aetiology of fever (13.8\%). They were especially prevalent at the beginning of the hot season, when the Harmattan, a very dry, hot, and sandy wind blows from the desert. Thus, the Harmattan may account for the second peak in February fever distribution. This phenomena, which is well documented in Burkina Faso [44], also facilitates meningococcal diffusion. For Africans living in Ouagadougou, pneumonias are the first aetiology of fever and represent $27.6 \%$ of all fevers [44].

\section{Chemoprophylaxis}

Only one malaria case was recorded in a "traveller" under appropriate and successfully administered chemoprophylaxis, according to the current French recommendations in 2006. These recommendations have since 
evolved, which is in accordance with this result, but only $69 \%$ of the travellers correctly took one.

\section{Clinical signs associated to the malaria}

With a malaria prevalence of only $22.6 \%$, a systematic treatment by febrile syndrome such as "Emergency Standby Treatment", as recommended for travellers going to remote places where access to medical care is unlikely to be within 24 hours, will lead in Burkina Faso to $77.4 \%$ of unnecessary treatments. A clinical diagnosis based on isolated fever, with a negative predictive value (NPV) of $91.9 \%$ and a positive predictive value (PPV) of $44 \%$ (Table 4), would result in $56 \%$ of unnecessary treatments and $22 \%$ of undiagnosed malaria infections. Such a clinical diagnosis would cause a diagnosis delay with potentially serious consequences. Other important clinical signs or combinations of signs do not allow us to justify a presumptive treatment. Isolated fever, present at the time of the examination, would be a strong factor of "suspicion of malaria" with a PPV of $66.7 \%$.

A reliable and systematic test for malaria diagnosis is necessary to judiciously dispense malaria therapies to a population of non-immune adults staying in an endemic area. The low malaria prevalence among fevers, as well as the clinical examinations' lack of sensibility and specificity, do not justify the risk of severe and unwanted side-effects, treatment resistance, heavy financial burdens associated with using new molecules, such as artemisinin-derivatives $[24,45,46]$, as well as delays in the diagnosis of other serious diseases [47-50].

Based on this data, Figure 3 attempted to define a decision algorithm in order to help physicians working in Burkina Faso.

\section{Conclusions}

The two most frequent fever pathologies found in adults travelling to Ouagadougou, namely digestive tract infections and malaria, should be the object of information and preventative measures prior to departure. For malaria, chemoprophylaxis proved to be effective in this study. However, only $69 \%$ of short-stay patients effectively took chemoprophylaxis. Travel to high-risk areas is increasing, and it is becoming increasingly important for physicians to provide good advice prior to departure.

At the facility, all patients with fever or "suspicion of fever" must systematically be evaluated with a reliable

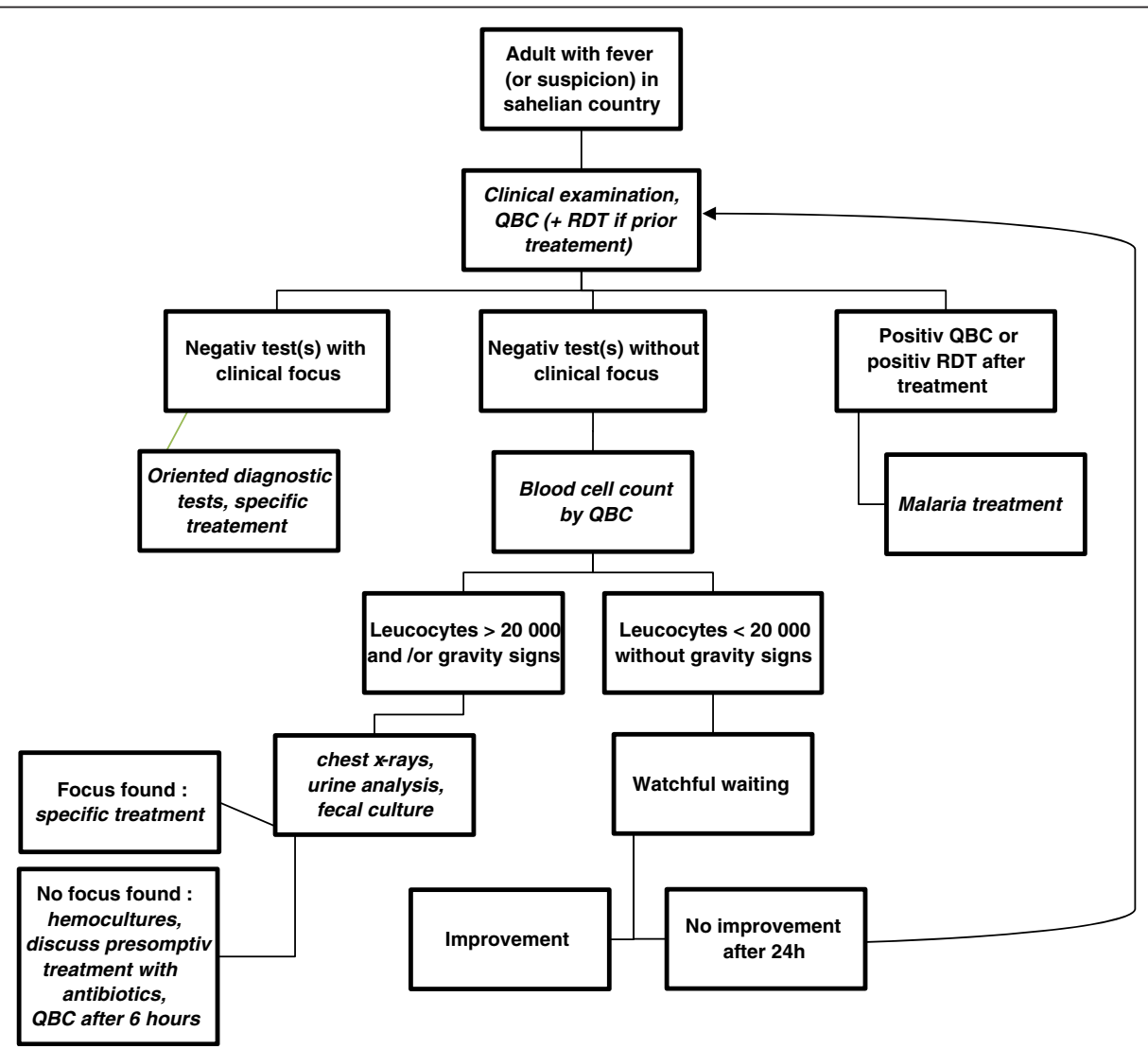

Figure 3 Management recommendation for febrile adults from non-malaria endemic countries living or travelling in Sahelian countries. 
malaria test prior to treatment. In this Sahelian context, the $\mathrm{QBC}$ seems to be the most reliable diagnosis test; the RDT still remains a feasible testing option, especially in the case of prior treatment. However, since malaria has an especially low prevalence in dry season, other aetiologies, such as pneumonias, must be considered without delay.

\author{
Abbreviations \\ $X^{2}$ : Chi-squared test; ENT: ear, nose, and throat; GTF: Giemsa-stained thick \\ film; NPV: Negative predictive value; OR: odds ratio; PPV: Positive predictive \\ value; QBC: Quantitative Buffy Coat; RDT: Rapid Diagnostic Test; t-test: \\ Student's test.
}

\section{Competing interests}

The authors have no conflict of interest to declare

\section{Authors' contributions}

SSS and SGP with help of EC participated in the study design and collected the samples; SSS conducted the review and analysis and wrote the first draft of the manuscript. AAB and SBS performed the GTF examination. All authors took part in the preparation and final approval of the manuscript.

\section{Acknowledgements}

The authors are very grateful to CMS personnel for their help and support with this study, especially to Chantal Kam, head nurse, Adele, the essentia secretary, and all the others physicians and nurses. The authors also would like to thank the Centre National de Recherche et de Formation sur le Paludisme de Ouagadougou personnel for their help and daily cheer!

Received: 15 February 2013 Accepted: 11 June 2013

Published: 2 August 2013

\section{References}

1. Snow RW, Craig MH, Deichmann U, le Sueur D: A preliminary continental risk map for malaria mortality among African children. Parasitol Today 1999, 15:99-104.

2. Robert V, Chippaux J, Dioamdé L: Le Paludisme en Afrique de l'Ouest: études entomologiques et épidémiologiques en zone rizicole et en milieu urbain. IRD Editions: ORSTOM; 1991.

3. Ouédraogo A, Tiono AB, Diarra A, Sanon S, Yaro JB, Ouedraogo $E$, Bougouma EC, Soulama I, Gansané A, Ouedraogo A, Konate AT, Nebie I, Watson NL, Sanza M, Dube TJT, Sirima SB: Malaria morbidity in high and seasonal malaria transmission area of Burkina Faso. PLoS One 2013, 8:e50036.

4. WHO: Global Malaria Programme, World malaria report 2012. Geneva: World Health Organization; 2012.

5. Snow RW, Craig M, Deichmann U, Marsh K: Estimating mortality, morbidity and disability due to malaria among Africa's non-pregnant population. Bull World Health Organ 1999, 77:624-640.

6. Becher $H$, Müller $\mathrm{O}$, Jahn A, Gbangou A, Kynast-Wolf $G$, Kouyaté B: Risk factors of infant and child mortality in rural Burkina Faso. Bull World Health Organ 2004, 82:265-273.

7. Direction générale de l'information et des statistiques sanitaires: Annuaire statistique 2009 de la santé. Ouagadougou, Burkina Faso: Ministère de la Santé; 2010:191.

8. Communauté française La France au Burkina Faso. [http://www.ambafrancebf.org/Communaute-francaise]

9. Romi R, Boccolini D, D'Amato S, Cenci C, Peragallo M, D'Ancona F, Pompa $M G$, Majori G: Incidence of malaria and risk factors in Italian travelers to malaria endemic countries. Travel Med Infect Dis 2010, 8:144-154.

10. Askling HH, Nilsson J, Tegnell A, Janzon R, Ekdahl K: Malaria risk in travelers. Emerg Infect Dis 2005, 11:436-441.

11. Bottieau E, Clerinx J, Schrooten W, Van den Enden E, Wouters R, Van Esbroeck M, Vervoort T, Demey H, Colebunders R, Van Gompel A, Van den Ende J: Etiology and outcome of fever after a stay in the tropics. Arch Intern Med 2006, 166:1642-1648.

12. Bottieau E, Clerinx J, Van den Enden E, Van Esbroeck M, Colebunders R, Van Gompel A, Van den Ende J: Fever after a stay in the tropics: diagnostic predictors of the leading tropical conditions. Medicine (Baltimore) 2007 86:18-25.

13. Siikamäki HM, Kivelä PS, Sipilä PN, Kettunen A, Kainulainen MK, Ollgren JP, Kantele A: Fever in travelers returning from malaria-endemic areas: don't look for malaria only. J Travel Med 2011, 18:239-244

14. Wilson ME, Weld LH, Boggild A, Keystone JS, Kain KC, von Sonnenburg F, Schwartz E: Fever in returned travelers: results from the GeoSentinel Surveillance Network. Clin Infect Dis 2007, 44:1560-1568.

15. Kortepeter MG, Seaworth BJ, Tasker SA, Burgess TH, Coldren RL, Aronson NE: Health care workers and researchers traveling to developing-world clinical settings: disease transmission risk and mitigation. Clin Infect Dis 2010, 51:1298-1305.

16. Odolini S, Parola P, Gkrania-Klotsas E, Caumes E, Schlagenhauf $P$, López-Vélez R, Burchard G-D, Santos-O'Connor F, Weld L, von Sonnenburg F, Field V, de Vries $P$, Jensenius M, Loutan L, Castelli F: Travel-related imported infections in Europe, EuroTravNet 2009. Clin Microbiol Infect 2012, 18:468-474.

17. Johnston V, Stockley JM, Dockrell D, Warrell D, Bailey R, Pasvol G, Klein J, Ustianowski A, Jones M, Beeching NJ, Brown M, Chapman ALN, Sanderson F, Whitty CJM: Fever in returned travellers presenting in the United Kingdom: recommendations for investigation and initial management. J Infect 2009, 59:1-18.

18. Leggat PA: Assessment of febrile illness in the returned traveller. Aust Fam Physician 2007, 36:328-332.

19. Lo Re V 3rd, Gluckman SJ: Fever in the returned traveler. Am Fam Physician 2003, 68:1343-1350

20. Blair JE: Evaluation of fever in the international traveler. Unwanted "souvenir" can have many causes. Postgrad Med 2004, 116:13-20. 29.

21. Ohrt C, Ohrt C, Purnomo OC, Sutamihardja MA, Tang D, Kain KC: Impact of microscopy error on estimates of protective efficacy in malariaprevention trials. J Infect Dis 2002, 186:540-546.

22. Tagbo O, Henrietta UO: Comparison of clinical, microscopic and rapid diagnostic test methods in the diagnosis of Plasmodium falciparum malaria in Enugu, Nigeria. Niger Postgrad Med J 2007, 14:285-289.

23. Matta S, Kantharia SL, Desai VK: Malaria diagnosis in private laboratories of Surat city: a laboratory based study. J Vector Borne Dis 2004, 41:76-79.

24. Zurovac D, Larson BA, Akhwale W, Snow RW: The financial and clinical implications of adult malaria diagnosis using microscopy in Kenya. Trop Med Int Health 2006, 11:1185-1194.

25. Dini L, Frean J: Quality assessment of malaria laboratory diagnosis in South Africa. Trans R Soc Trop Med Hyg 2003, 97:675-677.

26. Kilian AH, Metzger WG, Mutschelknauss EJ, Kabagambe G, Langi P, Korte R, von Sonnenburg F: Reliability of malaria microscopy in epidemiological studies: results of quality control. Trop Med Int Health 2000, 5:3-8.

27. Beljaev AE, Brohult JA, Sharma GK, Haque MA, Samantaray KC: Studies on the detection of malaria at primary health centres. Part I. Reliability of parasitological diagnosis by decentralized laboratories. Indian J Malariol 1985, 22:85-103.

28. Collier JA, Longmore JM: The reliability of the microscopic diagnosis of malaria in the field and in the laboratory. Ann Trop Med Parasitol 1983, 77:113-117.

29. Okell LC, Ghani AC, Lyons E, Drakeley CJ: Submicroscopic infection in Plasmodium falciparum-endemic populations: a systematic review and meta-analysis. J Infect Dis 2009, 200:1509-1517.

30. Raghavan K: Statistical considerations in the microscopical diagnosis of malaria, with special reference to the role of cross-checking. Bull World Health Organ 1966, 34:788.

31. Ochola L, Vounatsou P, Smith T, Mabaso M, Newton C: The reliability of diagnostic techniques in the diagnosis and management of malaria in the absence of a gold standard. Lancet Infect Dis 2006, 6:582-588.

32. Schlagenhauf $P$, Petersen $E$ : Standby emergency treatment of malaria in travelers: experience to date and new developments. Expert Rev Ant Infect Ther 2012, 10:537-546.

33. Chandramohan D, Carneiro I, Kavishwar A, Brugha R, Desai V, Greenwood B: A clinical algorithm for the diagnosis of malaria: results of an evaluation in an area of low endemicity. Trop Med Int Health 2001, 6:505-510.

34. Grimes DA, Schulz KF: Refining clinical diagnosis with likelihood ratios. Lancet 2005, 365:1500-1505.

35. Beckton Dickinson and Company: Manuel d'utilisation du QBC-Malaria-Test. Grenoble; 1993.

36. AllDiag: Manuel d'Utilisation version 3 du Palutop and Palutop 4+. Strasbourg; 2003. 
37. World Health Organization: Communicable Diseases Cluster: Severe falciparum malaria. Trans R Soc Trop Med Hyg 2000, 94(1):S1-S90.

38. BEH: Santé des voyageurs et recommandations sanitaires 2006, Bulletin épidémiologique hebdomadaire, Institut de veille sanitaire. 2006:153-176.

39. Laboratoire d'Analyses Médicales du Centre, Ougagdougou, Burkina Faso. [http://labocentre.bf/spip.php?page=article\&id_article=8]

40. De Pina JJ, Garnotel E, Hance P, Vedy S, Rogier C, Morillon M: Diagnostic du paludisme d'importation en France. Médecine et Maladies Infectieuses 2007, 37:710-715

41. QBC Diagnostics, Inc: [uww.qbcdiagnostics.com]

42. Moody A: Rapid diagnostic tests for malaria parasites. Clin Microbiol Rev 2002, 15:66-78.

43. Bell D, Wongsrichanalai C, Barnwell JW: Ensuring quality and access for malaria diagnosis: how can it be achieved? Nat Rev Microbiol 2006, 4:S7-S20.

44. Coulibaly C, Guiguemde T, Lamizana L, Ouedraogo J, Dabiret E: La part du paludisme dans les affections fébriles en milieu urbain de Ouagadougou (Burkina Faso, Afrique de l'Ouest). Ann Soc belge Méd trop 1991, 71:5-10.

45. World Health Organisation: Recent WHO Publications. Bull World Health Organ 1994, 72:525-532.

46. Jonkman A, Chibwe RA, Khoromana CO, Liabunya UL, Chaponda ME, Kandiero GE, Molyneux ME, Taylor TE: Cost-saving through microscopybased versus presumptive diagnosis of malaria in adult outpatients in Malawi. Bull World Health Organ 1995, 73:223-227.

47. English M, Punt J, Mwangi I, McHugh K, Marsh K: Clinical overlap between malaria and severe pneumonia in Africa children in hospital. Trans $R$ Soc Trop Med Hyg 1996, 90:658-662.

48. Gwer S, Newton C, Berkley J: Overdiagnosis and comorbidity of severe malaria in African children: a guide for clinicians. AmJTrop Med Hyg 2007, 77:6-13.

49. Reyburn $\mathrm{H}$ : Overdiagnosis of malaria in patients with severe febrile illness in Tanzania: a prospective study. BMJ 2004, 329:1212.

50. Van Dillen J, De Jager AJ, De Jong I, Wendte JF: Overdiagnosis of malaria in hospitalized patients in Namibia. Trop Doct 2007, 37:185-186.

doi:10.1186/1475-2875-12-270

Cite this article as: Schrot-Sanyan et al.: Malaria relevance and diagnosis in febrile Burkina Faso travellers: a prospective study. Malaria Journal 2013 12:270

\section{Submit your next manuscript to BioMed Central and take full advantage of:}

- Convenient online submission

- Thorough peer review

- No space constraints or color figure charges

- Immediate publication on acceptance

- Inclusion in PubMed, CAS, Scopus and Google Scholar

- Research which is freely available for redistribution 